\title{
PLME as a Cognitive Tool for Knowledge Achievement and Informal Learning
}

\author{
Tobias Nelkner, Johannes Magenheim, and Wolfgang Reinhardt \\ University of Paderborn, Germany \\ \{tobin, jsm, wolle\} @upb. de
}

\begin{abstract}
Since 2003 the research on Personal Learning Environments has increased. These environments support problem based, situated and informal learning in social networks within organisations and educational institutions and in subject related communities. The EU project MATURE [1] enhanced this idea with the concept of a Personal Learning and Maturing Environment (PLME), which shall support and foster learning and knowledge maturing. In this paper, we present a model that describes the maturing of knowledge and informal learning. Based on an example of changing a university study course, we present the personal, community and organisational perspective on knowledge maturing and informal learning. This leads to a derivation of requirements for a PLME implementation.
\end{abstract}

Keywords: Lifelong Learning, Open Flexible Learning, Informal Learning, Support Services for Learning, Knowledge Representation, Communication, Social Networks.

\section{Introduction}

There is a rapid change of contents, digital media and cognitive tools, partly in relation to teaching and learning methods in educational institutions and organisations, which demands a change in learning design. It also creates the need for a transformation from traditional structured into learning organisations. The required and necessary skills of knowledge workers (like students, teachers or lecturers) are capabilities in informal and lifelong learning. The introduction of ICT in education, for example, plays an important role in the development of informal learning processes. The main challenges are to gain access to new information and to perform rapid learning in situations of emerging problems. This comprises problem-based learning and situations of 'learning on demand'. The knowledge achieved during classroom lessons in secondary and vocational education is no longer suitable for the whole working life. Furthermore, knowledge can only partly be conveyed by traditional courses in classrooms or training on-the-job. Therefore, it is necessary to support and foster abilities for problem-based learning and lifelong learning as core competences supported by ICT even in traditional educational institutions. In fact, the knowledge worker, such as a teacher or student, should be able to participate in necessary changes and communication within his or her (educational) institution as 
well as following his or her individual objectives in a better way. The community of researchers in the area of ICT based support of lifelong learning and informal learning in education has increased. For example, the IFIP Agora [2] initiative does research on several aspects (e.g. ethical, individual, organisational) of lifelong learning and establishes social networks of practicioners and researchers. Hence, the need has emerged to provide a social network with software that supports informal learning processes and fosters the transformation of organisations into learning organisations.

Therefore, the four-year large scale EU funded IP project MATURE, which started in April 2008 within the 7th. Framework Programme, aims to develop a Personal Learning and Maturing Environment (PLME). This concept should support the idea of informal learning and working processes within organisational contexts of both the individual knowledge worker and the communities of knowledge workers (e.g. lecturers). The maturing process has to be clarified in order to provide (informal) learners with adequate services for their knowledge achievement. Furthermore, the maturing of knowledge should be made recognisable, visible and analysable in order to realise a high degree of learning success, personal customisation and work efficiency. Hence, in this paper we present a model of different instantiations of knowledge, such as documents, interaction and competences. Based on this model, we describe the maturing processes of various instantiations of knowledge from different social perspectives. By analysing these maturing processes, we derive requirements for a PLME implementation, which shall support individual learning in the workplace. This includes personal customisation of learning objects, personal knowledge achievement and connection, and the visualisation of social networks. Therefore, PLMEs should aggregate and integrate the functionality of existing and new social platforms, such as, for example, wikis or microblogging.

This paper is structured as follows: after the introduction, the underlying theory of knowledge maturing is explained. This is supplemented by an example of a transformation process that is based on individual experiences of stakeholders in educational institutions. By describing the change of a university degree programme, the multiple social layers of the model will be illustrated in an exemplary way. Based on these considerations, section 4 of the paper presents the derivation of a subset of functional requirements for a PLME. These requirements enable the PLME to support workers like lecturers in learning processes. The paper concludes in section 5 with conclusions and an outlook on further research.

\section{Knowledge Maturing and Instantiations of Knowledge}

Knowledge maturing as described, in this section, occurs always in the individuals' mind. Artefacts and social interactions are observable externalisations of knowledge. Nevertheless, an individual not only acts for themself, but almost always in a community or an organisation. Therefore, these (abstracted) perspectives have to be considered too. In order to describe a knowledge maturing model that comprises learning from the personal, community and organisational perspective, it is useful to present the basic idea for the individual level. After this we will extend the concept of knowledge maturing regarding two other levels. 
Figure 1 shows a model for describing the emergence of knowledge according to the theory of symbolic interactionism [3]. Two people with their own personal identity, and their own biography and personal attitudes communicate, each of them positioned in his or her social identity. These social identities may even overlap. The social identity relates to the different roles a person owns in a specific social context or within an organisation. The roles may be formal or informal and partly determine the behaviour, reactions, attitudes etc. of a person. Each person interprets the content of the

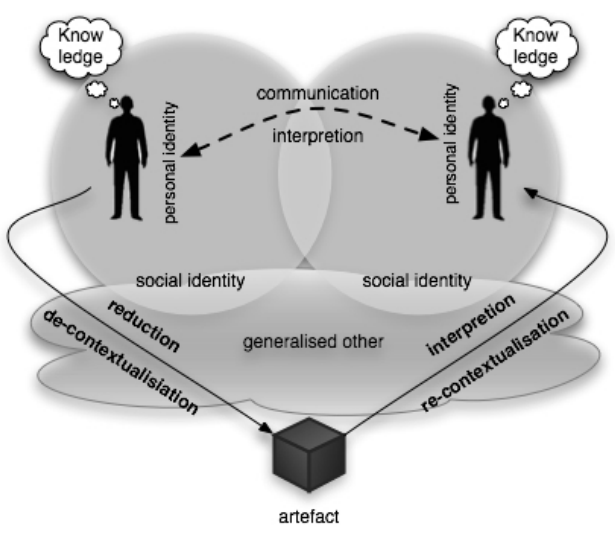

Fig. 1. A model for knowledge emergence communication by taking the view of his or her counterpart into account. By exploiting experiences, attitudes, knowledge and the interpretation of exchanged information, new knowledge can emerge within the consciousness of each person. This instantiation of knowledge that we call cognifact is closely linked to personal expertise as a result of formal and informal learning and communication processes.

The other relevant strand is the creation of artefacts, another instantiation of knowledge. Artefacts are all kinds of reproducible physical or digital results of an externalisation process, e.g. books, digital media or written laws and serve as an external memory [4]. Creating an artefact goes along with the abstraction from the subject domain and therefore is equivalent to a process of de-contextualisation of the content. By writing a paper for example, we often abstract from the reality-oriented scenarios we have in mind and generalise concepts from a concrete context into an adequate, but more abstract form. The result is a paper with de-contextualised content, which can become persistent and can be transferred to someone else. Therefore, the availability of artefacts is essential for sustainable knowledge maturing, which includes a process of re-contextualisation of the content by an individual. For example, if a person reads a book he or she interprets it with previous knowledge and may gain new knowledge within a different context. This re-contextualisation goes along with a possible blurring of the intented meanings of the book's author. Blumer [3] states that every action and behaviour always involves earlier experiences and knowledge. Therefore, the maturing of knowledge is contextually bound.

Furthermore, knowledge is not only represented in artefacts, but also in social interaction. Social interaction is usually guided by social norms and rules and is observable. This aspect provides a third instantiation of knowledge, the sociofacts. Individuals, who are communicating with each other, take into account the possible expectations of their counterpart. The generalised other is an abstract concept of normative mutual expectations and perspectives depending on the different roles and attitudes of the communicating partners (see fig. 1). The concept influences the deand re-contextualisation process by social norms and regulations. Moreover, social 
interaction leads to the creation of such rules. Since they are individually constructed they are part of the cognifacts while social relevant action and interaction of individuals on the basis of existing rules are assigned to the sociofacts. The unwritten rules of communication are informal, partly imprecise and not sanctioned by law. Nevertheless, assigned social interaction as sociofacts can lead to the maturing of laws and job-related rules. The outcomes of those processes like manifested rules and regulations are artefacts.

As shown above, knowledge maturing is not restricted to personal knowledge or artefacts, but also happens within social collaboration. Moreover, these three elements are firmly interlinked with each other. The technological triangle $[5,6]$ shows the connection between the three knowledge instantiations: artefacts, sociofacts and cognifacts (see figure 2). Unlike Engbring [6] we consider attitudes, norms and rules as parts of the cognifacts. Cognifacts may lead to new artefacts and sociofacts, whilst these on the other hand influence individual knowledge in form of cognifacts. As individuals are co-operating in

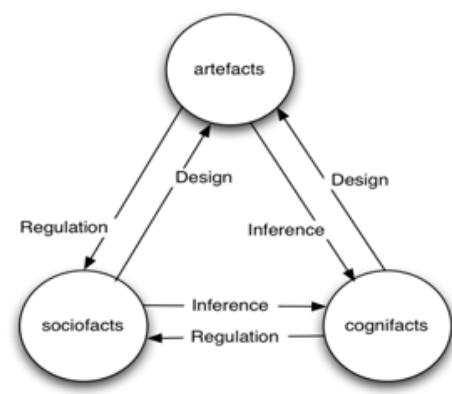

Fig. 2. Dependencies between knowledge instantiations communities and organisations, cognifacts may also be assigned to communities and organisations as an abstraction from the individual perspective.

We will examine these mutual dependencies by means of a Learning Management System (LMS). The increasing availability of LMSs has led to more computer-based communication and collaborative learning as a relevant sociofact in the area of Elearning. Individually achieved competences and qualifications are cognifacts and basically describe the ability to change one's behaviour as a result of sociofacts and the re-contextualisation of artefacts. Finally, on the content level, a LMS provides access to learning objects as a relevant instantiation of artefacts. Occuring mutual dependencies between the three instantiations might be: Good quality learning materials (artefacts) provided by the LMS may increase it's usage by students, which may also mean that communication facilities of the LMS are more intensively applied. The artefacts help to gain new competences (cognifacts). Sociofacts are created by more intensive use of the communication facilities. Furthermore, by mutual dependency the creation of sociofacts also regulate the creation of cognifacts. This accounts for student's competences (cognifacts) as well as their social interaction (sociofacts). Students' feedback to the tutors, given via the LMS, may after all contribute to the improvement of the quality of the learning objects (cognifacts). This approach seems to offer a proper explanation for the relevance of individual and collaborative learning within the process of knowledge maturing. Furthermore, it provides a concept for knowledge maturing that includes not only a personal perspective, but also takes community-related and organisational perspectives into account. The following section of the paper associates the model's personal dimension of knowledge maturing with the perspectives of the community and the organisation. 


\section{Social Perspectives of Knowledge Maturing}

As the model shows, knowledge maturing and informal learning depends not only on individuals, but also on societal influences and co-operation. Co-operation is an important fact within communities and organisations like universities. But working and learning in such co-operative environments shifts the perspective from the individual to the community and the organisation. Therefore, in this section the process of knowledge maturing from these three different perspectives by the means of the emerging transformation of a university study course is explained. In contrast to the personal perspective, which focuses on the acting person itself, the community perspective describes the results of informal (and probably not pre-defined) interpersonal interaction and more specified workflow processes. Furthermore, the organisational perspective focuses on interaction and processes aiming at the achievement of organisational goals. This includes organisational guidelines, welldefined processes or regular vocational trainings. These three perspectives do not include grading. They are equivalent, but provide different levels of knowledge maturing description. The process of change-management for a study course will give a more concrete example for these perspectives.

Table 1. Impact of the knowledge instantiations on the different layers

\begin{tabular}{|c|c|c|c|c|}
\hline & \multicolumn{3}{|c|}{ Levels } \\
\hline & & Personal perspective & Community perspective & $\begin{array}{l}\text { Organisational } \\
\text { perspective }\end{array}$ \\
\hline \multirow{3}{*}{ 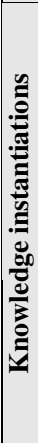 } & Artefacts & $\begin{array}{l}\text { (1) } \\
\text { Personal documents, } \\
\text { learning materials }\end{array}$ & $\begin{array}{l}\text { (4) Co-operatively created, } \\
\text { compileddocuments, e.g. E-mails, } \\
\text { Blogs, Wikis }\end{array}$ & $\begin{array}{l}\text { (7) } \\
\text { Authoritative documents, } \\
\text { e.g. study guidelines }\end{array}$ \\
\hline & Cognifacts & $\begin{array}{l}\text { (2) } \\
\text { Personal knowledge, } \\
\text { experience, attitudes, } \\
\text { norms, beliefs }\end{array}$ & $\begin{array}{l}\text { (5) } \\
\text { Individual perspective on } \\
\text { communication and co-operation } \\
\text { networks in a community }\end{array}$ & $\begin{array}{l}\text { (8) } \\
\text { Individual perspectives on } \\
\text { icommunication and } \\
\text { cooperation networks in } \\
\text { an organisation, HRM }\end{array}$ \\
\hline & Sociofacts & $\begin{array}{l}\text { (3) } \\
\text { Individual action with } \\
\text { regard to social norms, } \\
\text { realised learning } \\
\text { strategies }\end{array}$ & $\begin{array}{l}\text { (6) } \\
\text { Activities of community } \\
\text { members according to } \\
\text { co-operatively created (non) } \\
\text { formalised rules }\end{array}$ & $\begin{array}{l}\text { (9) } \\
\text { Interaction for change } \\
\text { management, application } \\
\text { of exam regulations }\end{array}$ \\
\hline
\end{tabular}

Assuming, a professor has realised that his course is not up-to-date concerning the content and that some procedural aspects lead to disadvantages for the students. Therefore, he initiates talks with his colleagues, which results in a change in process and in a restructuring of the whole study course.

Table 1 shows a matrix, which depicts the different knowledge instantiations from the three perspectives. A starting point can be the set of personal cognifacts. A professor has gained experiences with his courses and understands the different positive and negative aspects concerning the structure of the study course (field (2) in table 1). He has gained this knowledge in talks with other lecturers that made him aware of other concepts organising a study course (3). Consequently, he starts to change his course material with new research findings and, therefore, creates personal 
artefacts (1). Then, he starts talking about the assets and impacts of possible changes of the study course with fellow researchers or colleagues (mainly) from other universities. By expressing these ideas, he conveys his opinions and new ideas into the community. This can be done by writing e-mails ((4), creating artefacts) or during a round table discussion (sociofacts). As one possible result of the exchange of experiences and the discussion about the problems, the community may develop rules to handle the known problems (artefacts). While the talk and social interaction in the university are sociofacts (6), the emergent knowledge and its internalisation by the participating staff is described by cognifacts (5). As an abstraction, the community builds upon this knowledge as it emerges in its context. Consequently, every person builds his own knowledge. This is for cognifacts the same as for sociofacts and, therefore, these fields are greyed in the table. During this process of 'learning' within the community new artefacts can emerge. These might be e-mails or a common application to the administration, which represents a new concept and asks for a change process of the existing study course. On this level, also a personal generation of cognifacts and artefacts $(1,2)$ will take place, but these processes of knowledge achievment are included in the co-operatively created document, which describes the concept of the revised study course (4).

After having made the application for changing the study course, the knowledge and experiences of the community have to be conveyed at the organisational level. Its members need to communicate with the responsible administration and present their problems and possible solutions to convey the knowledge (8). For example, the IFIP provides a recommendation like the UNESCO curriculum for the use of ICT in education and the community uses this to achieve their objectives in negotiations with the administrators. Those administrators have to decide in which way, with which capacity and budget, the new study course could be organised. The maturing of knowledge at the community and organisational level does not show much difference. Both create experience and cognifacts in the minds of the participating people. Therefore, the two boxes $(5,8)$ are accented and assigned with a special role. But they differ in their objectives of knowledge creation and types of learning. At the community level most of the topic-related aspects can be discussed within the social network without any consequences. However, at the organisational level decisions must be put into practice considering the consequences for the organisation.

Once, the project has been accredited by the administration, all stakeholders have to develop plans and strategies for implementing the change process (9). The emerging artefacts at this level are documents, which contain and present the authoritative rules, such as the new study guidelines or examination schedules (7). These documents describe the future interaction and workflow in the future study course and are, thus, related to the sociofacts at the organisational level.

The knowledge maturing process affects different elements at different stages of the matrix shown above. With the lessons learned and newly achieved knowledge, cognifacts are created at the personal level, aggregated and improved at the community or organisational level. Sociofacts at the personal level may mature as results of interaction within the community level. Furthermore, sociofacts at the organisational perspective change with the given manifested rules.

An individual's effect on co-operatively generated cognifacts and sociofacts at the community and organisational perspective depend (besides his or her precognition) 
also on the persons role in a community or within an organisation. For example, a professor can act for change in the community in a different way. However, as he participates in change management at the organisational level, he is also part of the administration and has to consider different aspects. The study guidelines for the new study course will not be completely new, because positive experiences of former guidelines will be adopted. Knowledge maturing and process maturing is clearly recognisable at all these levels.

The example of an emerging change process in an organisation shows the dependencies between the different levels and the impact on the knowledge instantiations at the same, or adjacent, levels. The importance of informal learning for the generation of artefacts and sociofacts at the personal and community level emphasise the need for support by a Personal Learning and Maturing Environment. Based on this example section 4 derives requirements for the implementation of such an environment.

\section{Resulting Requirements for a PLME}

The idea of a PLME is drawn from further research in the field of Personal Learning Environments (PLEs) [7]. Personal Learning Environments should support and foster informal learning in social networks. Furthermore, the concept of PLEs concentrates on a self-organised learning environment and so the PLME will, too. This results in an implementation of loosely coupled tools and services that the user can organise and accomplish as he or she likes, or as his or her current task requires. Working with widgets in iGoogle is one example of a possibility to create a PLE. Some disadvantages of this application include persistence and sustainability. To overcome such barriers, a framework has to be designed, which is able to serve as a container for the tools and which supports interconnection and communication. The expected functionalities of such a set of tools are not only useful for teachers or tutors, but also in many cases will be important for the learners. Table 2 depicts functionalities that support the creation of the knowledge instantiations described above.

At the personal level the most important aspect is the personal knowledge achievement. For example, the creation of slides for a course requires the aggregation of knowledge from different sources (see table 2, field (1)). The challenge for a PLME is providing instant access to contextually relevant documents. In this way, a professor for learning design needs fast access to media objects dealing with various educational concepts he or she has to convey to his or her students. This can be achieved by a personal ontology, which serves for purposes of storing and organising the individually available material in a knowledge base (1). This ontology can be the result of an evaluation of customised cognifacts generated and used by the professor. The construction of the ontology should not only be the task of the user, but a semiautomatic process. This can be realised by an automatic metadata extraction and a semantic analysis of the artefacts, which are of relevance to the user. The semantic analysis could end up in a classification for a contextualized ontology. Together with the classification of documents, an efficient search engine has to be provided. This can be based on the extracted metadata combined with the information of the ontology. When enhancing the private desktop for knowledge achievement in this way, the search for information in 
Table 2. Derived functionalities for a PLME

\begin{tabular}{|c|c|c|c|c|}
\hline & \multicolumn{3}{|c|}{ Levels } \\
\hline & & $\begin{array}{l}\text { Personal } \\
\text { perspective }\end{array}$ & Community perspective & $\begin{array}{l}\text { Organisational } \\
\text { perspective }\end{array}$ \\
\hline \multirow{3}{*}{ 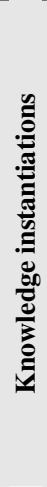 } & Artefacts & $\begin{array}{l}\text { (1) } \\
\text { - Personal databases, } \\
\text { individual } \\
\text { lightweight } \\
\text { ontologies }\end{array}$ & $\begin{array}{l}\text { (4) } \\
\text { - Collaborative tools (chat, } \\
\text { wikis, blogs) } \\
\text { - co-operative authoring } \\
\text { tools }\end{array}$ & $\begin{array}{l}\text { (7) } \\
\text { - Task and process } \\
\text { related database, } \\
\text { personalized FAQ }\end{array}$ \\
\hline & Cognifacts & $\begin{array}{l}(2) \\
\text { - E-portfolios } \\
\text { - unified online } \\
\text { profile or CV, } \\
\text { APML }\end{array}$ & $\begin{array}{l}\text { (5) } \\
\text { - Visualisation of } \\
\text { expertise, social networks } \\
\text { - expert recommending }\end{array}$ & $\begin{array}{l}(8) \\
\text { - same as (5), } \\
\text { competence } \\
\text { management, HRM } \\
\text { systems }\end{array}$ \\
\hline & Sociofacts & $\begin{array}{l}\text { (3) } \\
\text { - ToDo list, diary, } \\
\text { PIM }\end{array}$ & $\begin{array}{l}\text { (6) } \\
\text { - Evaluation of group } \\
\text { behaviour in order to } \\
\text { derive unwritten rules, } \\
\text { interaction structures }\end{array}$ & $\begin{array}{l}\text { (9) } \\
\text { - Tools for support of } \\
\text { process and change } \\
\text { management }\end{array}$ \\
\hline
\end{tabular}

the internet should be contextualised also. Thus, the user will be provided with further and more concise artefacts he or she is looking for.

As shown above, artefacts are not static over time, but mature. Therefore, a permanent versioning of the artefacts should be available (1). This function can serve several aspects. First, this would preserve the state of the artefacts. Furthermore, sustainable access is given, which provides the possibility to analyse the data within the overall database and might show connections between several artefacts. It would also be possible to support ontology maturing by assigning tags and logical rules to the cognifacts. Moreover, the creation and change of cognifacts can be achieved by developing a representation of the user's competences and attitudes (2), for example with an e-portfolio and the Attention Profiling Markup Language (APML) [8]. Supporting sociofacts on the person-oriented perspective can be achieved by fostering the interaction with people of the community or organisation. Thus, a to-do-list and a diary help foster this. Endowed with these functionalities, a PLME provides knowledge maturing mainly at the personal layer.

Regarding the community layer, the main challenge is to provide access to the user's social network. The most important aspects are realising the connection between artefacts and their authors, plus providing communication channels. For example, searching for a specific topic in e-mails is often undertaken by searching for an author we define to be an expert in this topic area. Once the e-mail has been found, it is easy to get into contact with the author in order to obtain more information about the subject (5). In the same way the possibility to get in contact with the author (or editor) of a document can support discussions and, therefore, fosters learning (4). For example, this can be achieved by starting a chat session or a phone call about the document. Additionally, the user needs some kind of visualisation of these networks. On the one hand, the visualisation of a social network and the topic-related communication (e.g. via e-mail) between its members can indicate knowledge about experts and expertise within a community (5). On the other hand, combining a topic 
network (which exists between the artefacts) with a social network helps to get new comprehension of the knowledge and the relations of members of the social network.

Tracking the behaviour of the users in various situations can support the sociofacts on this level by detecting unwritten rules. For example, a community agrees to use a special tag in the subject of the e-mails concerning a special topic for faster recognition of the e-mail's context. By analyzing the e-mails of the community, this rule could be detected. In order to support these sociofacts an e-mail client could recommend this tag every time the user writes to this community (6).

The organisational level includes the view on the aspects and processes of the overall organisation. This comprises mainly the support of formal processes, tasks and workflows, e.g. in the community perspective, the cognifacts on the organisational level can be supported by visualisations of social networks and expert recommending systems (8). This information can be used to get support e.g. when writing an article, but may also be integrated as an extension of a competence management system that allows to classify the knowledge workers according to their competences. The artefacts of the organisational level mainly consist of all formal documents an organisation, like a university has to manage (7). This includes information material for the students and lecturers, but also those related to the finance department and others. A process and task related management of these types of documents and an individually role-dependent view on these artefacts might ease the access to relevant knowledge. A lecturer, for example, only needs to have access to the study guidelines or rules for executing exams. However, an employee in the finance department needs access to different sources for processing the job. Therefore, a PLME has to provide a role-dependent personalized view of the artefacts at the organisational level and thus can contribute to the improvement and acceleration of tasks and workflows by triggering them to obey the lessons learnt. Sociofacts at the organisational level are represented by the organisational processes and change management (9). In our example, it could be supported by a tool that allows a view on the current status of the implementation of the new study course. Moreover, the lecturers that are involved in this process should have the possibility to (collaboratively) change the process. Communication facilities are also needed for this purpose to support tools for the negotiations between stakeholders.

Although we provided a list of functionalities, which shall support and foster informal learning within a PLME, there is not always a clear distinction between the separate fields of the matrix of social perspectives and knowledge instantiations. On the one hand, this is because the different perspectives depend on the context and the role of a knowledge worker. On the other hand, the transition from one perspective to another is not always strict and, therefore, the impact of such functionalities may affect several fields of the matrix in table 2. Nevertheless, some fundamental services, which should be provided by a PLME, were identified.

\section{Conclusion and Outlook}

Obviously, this is not a complete list and especially the connection between these functionalities has to be investigated further. Furthermore, the realisation of some of these functionalities is critical and hard to implement. For such sophisticated 
functionalities, it is indispensable to provide a capable server structure. However, this theoretical founded concept of a PLME depicts a roadmap for fostering and supporting informal learning within (educational) organisations. Furthermore, we have to state that PLME-supported informal learning can initiate and accelerate organisational changes. Moreover, it might help to transform them from a traditional structure into a learning organisation. The illustrative case of a PLME used in this paper provides one approach in which to achieve these goals. Nevertheless, it is noted that the role of the organisational perspective has to be explored in more depth. The most important next step will be the implementation of prototypes to evaluate user acceptance.

\section{References}

1. Mature EU-IP Project, http: / /mature-ip.eu (last visited: 15.01.2009)

2. AGORA, IFIP, http://www.ifip-tc3.net/article.php3?id_article=146 (last visited: 15.01.2009)

3. Blumer, H.: Der methodologische Standort des symbolischen Interaktionismus. In: Soziologen, A.B. (Hrsg.), Alltagswissen, Interaktion und gesellschaftliche Wirklichkeit, Bd. 1. Reinbek bei Hamburg, Rowohlt (1973)

4. Slawik, R.K.: Artifacts as external memory. In: Floyd, C., et al. (eds.):

5. Krohn, W.: Zum historischen Verständnis der Technik. In: Technik-Kultur-Arbeit, Seite, 27-34 (1992)

6. Engbring, D.: Informatik im Informatik im Herstellungs- und Nutzungskontext. PhD thesis, University of Paderborn (2003)

7. Attwell, G.: The Personal Learning Environments - the future of eLearning? eLearning Papers 2(1) (2007)

8. Attention Profiling Markup Language, http : / / apml . org/ (last visited: 15.01.2009) 